\title{
Reducing Anxiety in Children: Creating Emotionally Safe Places for Children to Learn
}

\author{
Eugene Geist* \\ Professor, Ohio University, USA
}

*Corresponding author: Eugene Geist, Professor, Ohio University, USA.

Received Date: October 30,2019

Published Date: November 06, 2019

\section{Introduction}

As we enter the third decade of the $21^{\text {st }}$ century, research is suggesting that children are not only dealing a great deal of anxiety caused directly by school (ref). Academic anxiety related to learning is increasing due to highly stressful teaching methods, reduction of recess, too much homework and an over reliance on testing [1,2]. However, the anxiety is also produced by the stress of the school environment. For many children, armed police officers patrol the hallways and "active shooter drills" are a regular part of every day. Add to this the pervasive presence of bullying, a reduction in the time that children get to engage in self-directed activities and arts based programming $[3,4]$, and an anti-democratic culture in schools [5] and you end up with places that breed anxiety and are not emotionally safe for children.

\section{Anxiety and Academic Achievement}

Anxiety toward school is a growing barrier for many children to achievement. For many children, negative attitudes toward subjects such as mathematics and science begins early a child's schooling, sometimes even before they enter kindergarten. As children enter formal schooling, the learning process sometimes takes a turn for the worse, especially for girls and minorities. Studies have shown that at this time in children's learning of mathematics and science, textbooks and high stakes testing take over the process of teaching and the focus shifts from construction of concepts using children's own thinking to teacher imposed methods of getting the correct answer [6]. Teachers begin to focus on repetition and speed or "timed tests" as important tools for improving academic prowess and skill. This overreliance on timed tests, standardized assessments, achievement at all costs and other high stakes approaches to teaching mathematics reinforce the negative attitude toward schooling that many children have developed in the early years of life [7-9]).

\section{Physical Safety Anxiety}

In the past decade, the prevalence of mass shootings in schools has increased. While solutions to the problem of school shootings is complex and beyond the scope of this article, we do need to recognize that many of the steps taken to keep children physically safe at school such as "active shooter drills" do lead to increased anxiety in children. Schools need to be aware that these types of drills do have an adverse effect on children's emotional wellbeing and take steps to help children deal with the anxiety of living with such a threat. The rise in anxiety in school children can lead to a rise in undesirable behaviors. Janson and King [10] noted:

A classroom characterized by warmth and affirmation may be the only place where children can safely express their true feelings. In practical terms, this makes emotional security in the classroom a prerequisite to helping each child learn and grow into a socially competent individual (p.3). However, these are all issues that can be addressed and fixed by caring administrators that are committed to making schools safe and supportive places for all children. Reducing the anxiety brought about by the school environment means changing the environment so that it is more student centered, emotionally relevant and open to the many ways in which children can express themselves $[11,12]$. The emotional wellbeing of students is often overlooked in modern school culture however this attitude must change. We must concern ourselves with the development of the whole child and ensure that our teaching methods and the school environment that we create does not create unnecessary anxiety in children.

\section{Acknowledgement}

None.

\section{Conflict of Interest}

No conflict of interest. 


\section{References}

1. Beilock SL (2008) Math Performance in Stressful Situations. Current Directions in Psychological Science 17(5): 339-343.

2. Teicher MH, Ito Y, Glod CA, Schiffer F, Gelbard HA (1996) Neurophysiological mechanisms of stress response in children (C. Pfeffer, Edn.), Washington, DC, US: American Psychiatric Association, USA, pp. 59-84.

3. Brown ED, Benedett B, Armistead ME (2010) Arts enrichment and school readiness for children at risk. Early Childhood Research Quarterly 25(1): 112-124.

4. Felsman P, Seifert CM, Himle JA (2019) The use of improvisational theater training to reduce social anxiety in adolescents. Arts in Psychotherapy 63: 111-117.

5. Gray P (2017) Self-Directed Education-Unschooling and Democratic Schooling. Oxford Research Encyclopedia of Education.

6. Breinholst S, Tolstrup M, Esbjørn BH (2019) The direct and indirect effect of attachment insecurity and negative parental behavior on anxiety in clinically anxious children: It's down to dad. Child \& Adolescent Mental Health 24(1): 44-50.
7. Ahlen J, Lenhard F, Ghaderi A. (2019) Long-Term Outcome of a Cluster-Randomized Universal Prevention Trial Targeting Anxiety and Depression in School Children. Behavior Therapy 50(1): 200-213.

8. Kamii C (1990) Achievement testing in the early grades the games grown-ups play. Washington, D.C: National Association for the Education of Young Children.

9. Tsui JM, Mazzocco MMM (2007) Effects of Math Anxiety and Perfectionism on Timed versus Untimed Math Testing in Mathematically Gifted Sixth Graders. Roeper Review 29(2): 132-139.

10. Janson GR, King MA (2006) Emotional Security in the Classroom: What Works for Young Children. Journal of Family and Consumer Sciences 98(2): 70-74.

11. Bilaç Ö, Ercan ES, Uysal T, Aydin C (2014) The Prevalence of Anxiety and Mood Disorders, and Demographic Characteristics in Elementary School Students. Turkish Journal of Psychiatry 25(3): 171-180.

12. Malboeuf-Hurtubise C, Lacourse E, Herba C, Taylor G, Amor LB (2017) Mindfulness-based Intervention in Elementary School Students with Anxiety and Depression: A Series of n-of-1 Trials on Effects and Feasibility. Journal of Evidence-Based Complementary \& Alternative Medicine 22(4): 856-869. 